\title{
Adjuvant pamidronate therapy prevents the development of bone metastases in breast cancer patients with four or more positive nodes
}

\author{
IKUO KOKUFU ${ }^{1}$, NORIO KOHNO ${ }^{2,3}$, MASAYUKI YAMAMOTO ${ }^{1}$ and SHINTARO TAKAO $^{3}$ \\ ${ }^{1}$ Department of Surgery, Itami City Hospital, Itami 664-8540; ${ }^{2}$ Department of Breast Oncology, Tokyo Medical University, \\ Tokyo 160-0023; ${ }^{3}$ Department of Breast Oncology, Hyogo Medical Center for Adults, Akashi 673-8558, Japan
}

Received April 23, 2009; Accepted August 17, 2009

DOI: 10.3892/ol_00000044

\begin{abstract}
Bisphosphonates are strongly efficacious in inhibiting osteoclast bone resorption and have beneficial effects on bone metastasis. Due to their mechanism of action, bisphosphonates are expected to prevent the development of bone metastases in breast cancer patients. Pamidronate is a potent inhibitor of osteoclast activity. We examined whether pamidronate was able to prevent the development of bone metastases in breast cancer patients at high risk for bone metastasis. Between 1997 and 2001, 90 patients with primary breast cancer with $\geq 4$ positive nodes were assigned to receive $45 \mathrm{mg}$ pamidronate 4 times every 2 weeks (33 patients) or standard follow-up (57 patients) based on patient self-preference. Patients underwent surgery and adjuvant therapy. The characteristics of the patients in the two groups were well-balanced. The median follow-up period was 5 years. Bone metastases were detected in $12.1 \%$ of patients in the pamidronate group and $40.4 \%$ in the control group ( $\mathrm{p}=0.005)$. Distant metastases (36.4 vs. $56.1 \%, \mathrm{p}=0.071)$ and non-osseous metastases (33.3 vs. $52.6 \%, \mathrm{p}=0.077$ ) were detected at a lower frequency in the pamidronate group. Thus, the rate of bone metastasis-free survival was significantly higher in the pamidronate group ( 85.9 vs. $64.0 \%$ at 5 years, $\mathrm{p}=0.023$ ). Overall and disease-free survival rates did not differ between the two groups. In the pamidronate group, the incidence of bone metastases was significantly reduced and bone metastasisfree survival was significantly higher. Adjuvant pamidronate therapy therefore prevents the development of bone metastases in breast cancer patients with $\geq 4$ positive nodes.
\end{abstract}

\section{Introduction}

In breast cancer patients, bone is the most frequent site of distant metastasis. Once the destruction of bone has progressed,

Correspondence to: Dr Norio Kohno, Department of Breast Oncology, Tokyo Medical University, 6-7-1 Nishi-Shinjuku, Shinjuku-ku, Tokyo 160-0023, Japan

E-mail: nkohno@tokyo-med.ac.jp

Key words: adjuvant therapy, bisphosphonate, bone metastases, breast cancer, pamidronate skeletal complications occur with increased pain, immobility and deterioration of quality of life. The pathogenesis of bone metastases is not fully understood, but it is thought that breast cancer cells produce osteoclast-activating factors, which induce the osteoclast resorption of bone, leading to the development of lytic bone disease (1). Bisphosphonates strongly inhibit osteoclast bone resorption and have beneficial effects on bone metastases (2). They promote apoptosis not only in osteoclasts, but also in tumor cells $(3,4)$. They also have direct cytotoxic effects on breast cancer cell lines and fresh breast cancer tumor tissue (5). Bisphosphonates activate $\gamma \delta \mathrm{T}$-cell proliferation which contributes differently to the host immune defense (6). They also inhibit angiogenesis and matrix metalloproteinase activity which are related to the processes of tumor growth, invasion and metastasis (7). Based on these mechanisms of action, bisphosphonates are expected to prevent the development of bone metastases (8).

In an experimental in vivo study, risedronate (thirdgeneration bisphosphonate) reduced the development of bone metastases in nude mice either by the simultaneous inoculation of the human breast cancer cell line, MDA-231, or the prophylactic administration prior to MDA-231 cell inoculation (9). Furthermore, in an in vitro study, potent bisphosphonates (such as pamidronate and alendronate) inhibited the adhesion of breast cancer cells to cortical and trabecular bone (10). These studies suggest that bisphosphonates may be useful not only in the treatment of skeletal complications, but also in preventing the development of bone metastases. If preventive therapy has beneficial effects on the development of bone metastases, this will significantly impact the patient quality of life.

Pamidronate, a second-generation bisphosphonate, is a potent inhibitor of osteoclast activity. We initiated a preliminary study to examine whether adjuvant pamidronate therapy was able to prevent or delay the development of bone metastases in breast cancer patients at high risk for bone metastasis.

\section{Materials and methods}

Patients. This preliminary study was carried out at the Itami City Hospital and Hyogo Medical Center Hospital for Adults; beginning in 1997 with the June enrollment of patients and ending in November 2001. Ambulatory 20 years of age or older 
women with breast cancer, who were histologically proven to have $\geq 4$ positive nodes, were enrolled. Patients were ineligible for the study if they had received primary chemotherapy prior to surgery. This study was in accordance with the Helsinki Declaration (1964, amended in 1975 and 1983). Fully informed consent was obtained from the subjects enrolled. Although this study was designed as a randomized controlled trial, at the time it was performed it was very difficult to carry out a randomized trial in Japan. Japanese patients were unwilling to be randomly assigned to treatment groups and refused randomization. We therefore used the best available design with non-randomized assignment based on patient preference. A total of 90 patients were assigned either to treatment with pamidronate (33 patients) or to the control group (57 patients) by patient preference. Pamidronate $(45 \mathrm{mg})$ was administered intravenously every 2 weeks (standard use in Japan) for a total of 4 infusions. The infusion rate was consistent with the currently recommended treatment schedule for patients with hypercalcemia. Adjuvant therapy was performed in each hospital. Estrogen (ER) and progesterone receptor (PgR) assays were performed on the cytosol of each specimen by solid-phase enzyme immunoassay. Primary endpoints of this study were: i) reduction of the incidence of bone metastases and ii) the delay in the appearance of bone metastases in breast cancer patients with $\geq 4$ positive nodes. These patients were at high risk for bone metastases. Patients were included in the intent-to-treat analysis.

Treatment. The primary surgical treatment consisted of breast-conserving surgery (plus 50 Gy radiation to the breast) or mastectomy with axillary dissection. Pamidronate $(45 \mathrm{mg}$ ) was administered over a 45-min intravenous infusion every 2 weeks for a total of 4 times. Adjuvant systemic therapy was based on the protocols of each center and all 90 patients received chemotherapy. The most frequently used regimens were anthracycline combinations (60 patients; 66.7\%). CAF therapy [doxorubicin $\left(20 \mathrm{mg} / \mathrm{m}^{2}\right.$, days 1 and 8$), 5$-fluorouracil (500 mg/m² days 1 and 8) and cyclophosphamide (100 mg for 14 days orally)] was used in 55 patients $(61.1 \%)$. CEF therapy [epirubicin $\left(60 \mathrm{mg} / \mathrm{m}^{2}\right.$, day 1$)$, 5-fluorouracil $\left(500 \mathrm{mg} / \mathrm{m}^{2}\right.$, days 1 and 8$)$ and cyclophosphamide (500 $\mathrm{mg} / \mathrm{m}^{2}$, days 1 and 8)] was used in 5 patients $(5.6 \%)$. CMF therapy [methotrexate (40 $\mathrm{mg} / \mathrm{m}^{2}$, days 1 and 8$), 5$-fluorouracil (500 mg/m², days 1 and 8 ) and cyclophosphamide (100 mg for 14 days orally)] was used in 28 patients $(31.1 \%)$. Uracil and tegafur $(400 \mathrm{mg})$ were given orally every day for 2 years. The use and type of chemotherapy were evenly distributed between the pamidronate and control groups. Tamoxifen $(20 \mathrm{mg} /$ day) was provided for 5 years to 37 patients $(41.1 \%)$ who were hormonal receptor-positive. If metastases were confirmed, appropriate cytotoxic or hormonal therapies were used according to the treatment protocols of each centre.

Follow-up. Follow-up investigations were carried out in each centre. During the second year of treatment, patients continued to be studied at 2-month intervals, with a physical examination performed at every visit. Basic laboratory tests (blood counts, liver enzymes, serum creatinine, calcium, electrolytes and tumor antigen) were performed every 2 months. At entry into the study, it was confirmed that patients had no distant metastases. Bone scintigraphy was repeated every 6 months. Bone scintigraphy was performed at any time bone metastases were clinically suspected. If abnormal uptake was detected on bone scintigraphy, additional computed tomography and/or magnetic resonance imaging was performed to confirm bone metastases. At each center, radiological bone surveys were received by radiologists who were unaware of the patient's treatment. Chest X-ray, ultrasonography of the liver and chest, and abdominal computed tomography examinations were performed every 6 months. Adverse events were recorded and graded according to the National Cancer Institute Common Toxicity Criteria.

Statistical analysis. The data were last updated in August 2004. The Chi-square test was used to compare prognostic factors between the groups. Fisher's exact test was used for between-treatment comparison of the incidence of the development of metastases (distant, bone, visceral and non-osseous), as well as the incidence of death. Time from surgery to the appearance of metastases was estimated by the Kaplan-Meier method and compared with the log-rank test and generalized Wilcoxon test. Tests were two-sided. $\mathrm{P}<0.05$ was considered to be statistically significant.

\section{Results}

Thirty-three patients received adjuvant pamidronate therapy and 57 patients comprised the control group. The pamidronate and control groups were well-balanced for the clinicopathological characteristics of age, tumor size, nodal status, menopausal status, hormonal status and type of chemotherapy (Table I).

At the time of data cut-off, the median follow-up period was 1834 days (890-2149 days) in the pamidronate group and 2489 days (927-3004 days) in the control group. Distant metastases were detected in 12 patients $(36.3 \%)$ in the pamidronate group and in 32 patients $(56.1 \%)$ in the control group $(\mathrm{p}=0.071$; Table II). Bone metastases were detected in 4 patients $(12.1 \%)$ in the pamidronate group and in 18 patients $(31.6 \%)$ in the control group. The incidence of bone metastasis was significantly lower in the pamidronate than in the control group $(\mathrm{p}=0.005)$. Non-osseous (visceral and local) metastases were detected in 11 patients $(33.3 \%)$ in the pamidronate group and in 30 patients (52.6\%) in the control group ( $\mathrm{p}=0.077)$. Visceral metastases were detected in 10 patients $(30.3 \%)$ in the pamidronate group and in 24 patients $(42.1 \%)$ in the control group. Seven patients (21.2\%) in the pamidronate group, as well as 17 patients (39.8\%) overall succumbed to the disease $(\mathrm{p}=0.373)$.

The Kaplan-Meier analysis showed that bone metastasisfree survival at 5 years was $85.9 \%$ in the pamidronate group and $64.0 \%$ in the control group. Bone metastasis-free survival was significantly higher in the pamidronate group than in the control group $(p=0.023$; Fig. 1). However, no significant differences were noted between the two groups in overall, disease-free and non-osseous metastasis-free survival (Figs. 2, 3 and 4).

Pamidronate was well-tolerated. No renal or gastrointestinal side effects were observed. No serious adverse events believed to be related to pamidronate occurred. The only side effects were asymptomatic hypocalcemia (grade 1) in 2 patients and transient fever $\left(<38^{\circ} \mathrm{C}\right)$ in 3 patients. 
Table I. Patient characteristics in the pamidronate and control groups.

\begin{tabular}{|c|c|c|c|}
\hline & $\begin{array}{l}\text { Pamidronate group } \\
\qquad(\mathrm{n}=33)\end{array}$ & $\begin{array}{l}\text { Control group } \\
\qquad(\mathrm{n}=57)\end{array}$ & p-value \\
\hline Age & & & 0.8233 \\
\hline Median & $54(34-71)$ & $50(35-84)$ & \\
\hline Tumor status & & & 0.1532 \\
\hline $\mathrm{T} 1$ & $5(15.2 \%)$ & $8(14.0 \%)$ & \\
\hline $\mathrm{T} 2$ & $14(42.4 \%)$ & $25(43.9 \%)$ & \\
\hline $\mathrm{T} 3$ & $6(18.2 \%)$ & $19(33.3 \%)$ & \\
\hline $\mathrm{T} 4$ & $6(18.2 \%)$ & $3(5.30 \%)$ & \\
\hline Unknown & $2(6.5 \%)$ & $2(3.50 \%)$ & \\
\hline Metastatic lymph nodes & & & 0.2552 \\
\hline Median & $16(4-53)$ & $11(4-47)$ & \\
\hline Estrogen receptor status & & & 0.3797 \\
\hline Positive & $16(48.5 \%)$ & $21(36.8 \%)$ & \\
\hline Negative & $17(51.5 \%)$ & $33(57.9 \%)$ & \\
\hline Unknown & & $3(5.30 \%)$ & \\
\hline Progesterone receptor status & & & 0.6928 \\
\hline Positive & $13(39.4 \%)$ & $19(33.3 \%)$ & \\
\hline Negative & $20(60.6 \%)$ & $35(61.4 \%)$ & \\
\hline Unknown & & $3(5.30 \%)$ & \\
\hline Menopausal status & & & 0.4632 \\
\hline Premenopausal & $13(39.4 \%)$ & $27(47.4 \%)$ & \\
\hline Postmenopausal & $20(60.6 \%)$ & $30(52.6 \%)$ & \\
\hline Chemotherapy & & & 0.3534 \\
\hline CAF or CEF & $20(60.6 \%)$ & $40(70.2 \%)$ & \\
\hline Others & $13(39.4 \%)$ & $17(29.8 \%)$ & \\
\hline
\end{tabular}

CAF, cyclophosphamide, doxorubicin and 5-fluorouracil; CEF, cyclophosphamide, epirubicin and 5-fluorouracil.

Table II. Incidence of metastatic disease and death in the pamidronate and control groups.

\begin{tabular}{lccc}
\hline & $\begin{array}{c}\text { Pamidronate group } \\
(\mathrm{n}=33)\end{array}$ & $\begin{array}{c}\text { Control group } \\
(\mathrm{n}=57)\end{array}$ & $\mathrm{p}$-value \\
\hline Distant metastases & $12(36.3 \%)$ & $32(56.1 \%)$ & 0.071 \\
Bone metastases & $4(12.1 \%)$ & $23(40.4 \%)$ & 0.005 \\
Non-osseous metastases & $11(33.3 \%)$ & $30(52.6 \%)$ & 0.077 \\
Visceral metastases & $10(30.3 \%)$ & $24(42.1 \%)$ & 0.266 \\
Death & $7(21.2 \%)$ & $17(29.8 \%)$ & 0.373 \\
\hline
\end{tabular}

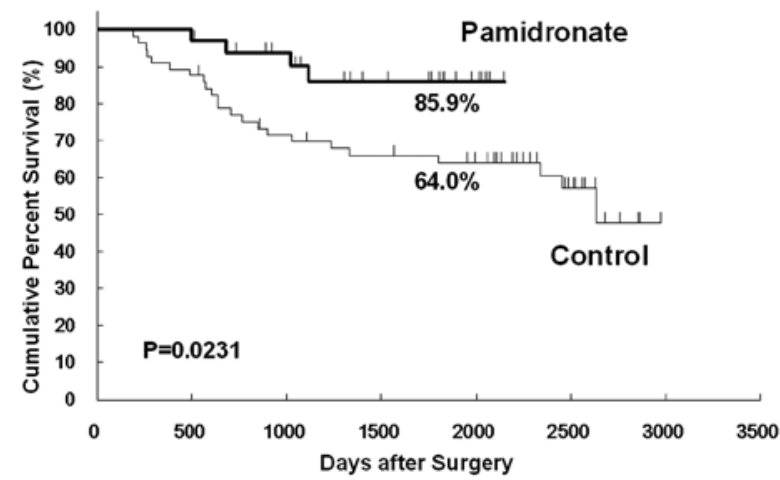

Figure 1. Bone metastasis-free survival in the pamidronate and control groups.

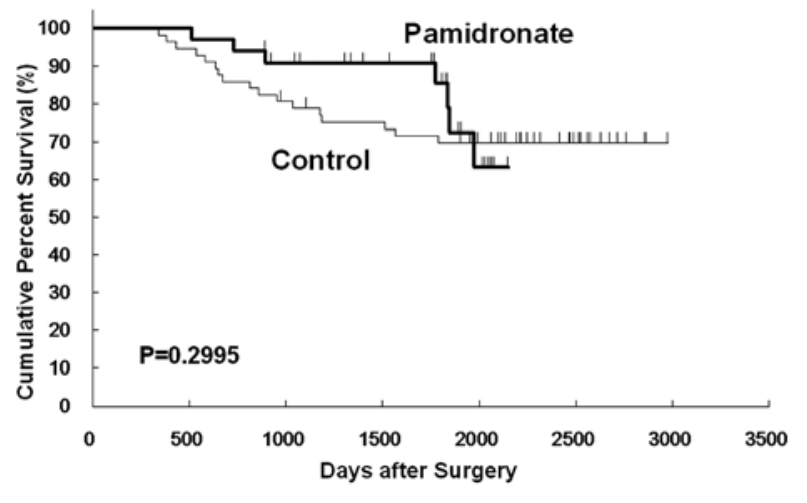

Figure 2. Overall survival in the pamidronate and control groups. 


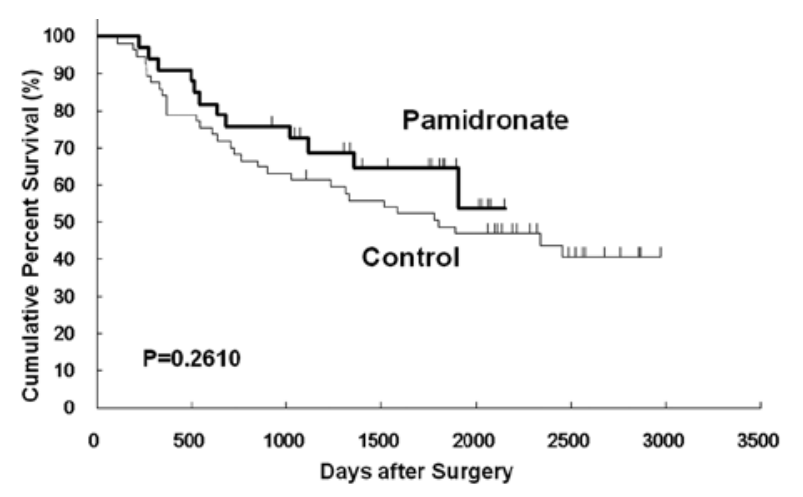

Figure 3. Disease-free survival in the pamidronate and control groups.

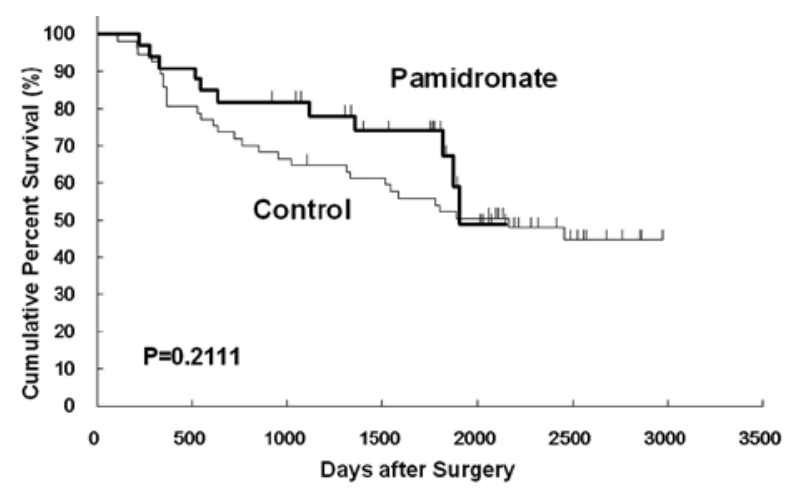

Figure 4. Non-osseous metastasis-free survival in the pamidronate and control groups.

\section{Discussion}

Bisphosphonates are very effective for bone metastases in breast cancer patients. They relieve the pain of bone metastases and improve quality of life for the patient. Prevention of the development of bone metastases will have a great impact on the course of disease in breast cancer patients. However, it is unclear whether bisphosphonates have a beneficial effect on the development of bone metastases in breast cancer. Three clodronate adjuvant prevention trials have been reported. Diel et al were the first to report on an adjuvant bisphosphonate study in 302 patients who had primary breast cancer and cancer cells in the bone marrow, as identified by immunocytological studies (11). These patients were randomized to receive clodronate at a dose of $1600 \mathrm{mg} /$ day for 2 years, or not to receive any clodronate. With a median follow-up of 36 months, the incidences of distant (13 vs. $29 \%, \mathrm{p}<0.001$ ), bone ( 8 vs. $17 \%$, $\mathrm{p}=0.003$ ) and visceral metastases ( 8 vs. $19 \%, \mathrm{p}=0.003$ ) were significantly lower in the clodronate group than in the control group. Metastasis-free and overall survival benefit were significant in the clodronate group $(\mathrm{p}=0.001)$. Diel et al updated their report at the May 2000 and June 2004 ASCO meetings (both in New Orleans, LA) $(12,13)$. Incidences of bone and non-osseous metastases were similar in the two groups. Survival was found to be significantly higher in the clodronate group ( $\mathrm{p}<0.049)$ at 103 months of follow-up. Powles et al reported on a larger study that included 1069 primary operable breast cancer patients who were randomized to receive either clodronate $1600 \mathrm{mg}$ /day or a placebo for 2 years (14). There was no significant reduction in the occurrence of bone metastases for the total follow-up period. However, during the medication period, a significant reduction in this parameter in the clodronate group ( 2.3 vs. $5.2 \%, \mathrm{p}=0.016)$ was noted. The rate of occurrence of non-osseous metastases was similar in the two groups, but there was a significant reduction in survival in the clodronate group ( 83 vs. 79\%, p=0.047). Powles et al updated their report at the June 2004 ASCO meeting (15). Clodronate significantly reduced bone metastases not only during the medication period ( 2 years, $\mathrm{p}=0.031$ ), but also during the entire study period ( 5 years, $\mathrm{p}=0.043$ ). Clodronate significantly improved survival at 10 years $(\mathrm{p}=0.048)$. On the other hand, Saarto et al reported a deleterious effect of adjuvant clodronate therapy. Two hundred and ninety-nine women with node-positive breast cancer were randomized to receive clodronate $1600 \mathrm{mg}$ /day for 3 years, or no clodronate with adjuvant therapy (16). With a minimum follow-up of 5 years, bone metastases were equally detected in the clodronate group (21 vs. 17\%), and the rate of development of non-skeletal metastases was significantly higher in the clodronate group (43 vs. $25 \%, \mathrm{p}=0.0007$ ). Furthermore, overall and diseasefree survival were significantly lower in the clodronate group (overall survival, 70 vs. $83 \%, \mathrm{p}=0.009$; disease-free survival, 56 vs. $71 \%, \mathrm{p}=0.007$, respectively). However, there was no significant difference in either overall or distant disease-free survival with adjustment data by PgR status because of the present imbalance between the two groups in $\mathrm{PgR}$ status. The report was updated at the June 2004 ASCO meeting (17). Bone metastases were similar in the two groups, but the incidence of non-skeletal metastasis was significantly higher in the clodronate group $(\mathrm{p}=0.005)$. Ten-year disease-free survival was lower in the clodronate group $(p=0.01)$, especially in ER-negative patients. No significant difference in overall survival was found between the two groups. In the present study, we demonstrated that adjuvant pamidronate therapy significantly decreased the incidence of the development of bone metastases, and prolonged bone metastasis-free survival in patients with $\geq 4$ positive nodes. There was a trend toward a decrease in the incidence of distant and visceral metastases in the pamidronate group, but no significant difference was noted between the two groups with regard to the overall survival rate.

The discrepancy findings among the above-mentioned studies appeared to result from the use of different patient populations and regimens of adjuvant therapy. The study by Powles et al consisted of broad stage I-III breast cancer patients, including those who received only radiation or no axillary dissection ( $1 / 3$ of all patients). Some of the patients appeared not to require adjuvant therapy. This population appeared to be at very low risk for bone metastases. It is possible that inclusion of this low-risk population reduced the statistical power in the detection of a beneficial effect of adjuvant clodronate therapy. The candidates for inclusion in the present study were primary breast cancer patients with $\geq 4$ positive nodes. The Japanese Breast Cancer Society classified $\geq 4$ positive node as $n 1 \beta$ and $\leq 3$ positive nodes as $n 1 \alpha$ prior to the initiation of this study. Patients with $\geq 4$ positive nodes were considered to be a high-risk patient population compared to those who were node-negative or had $\leq 3$ positive nodes. 
The International (Ludwig) Breast Cancer Study Group also demonstrated that patients with $\geq 4$ positive nodes were at high risk for bone metastasis and may thus benefit from preventive treatment against bone metastasis with bisphosphonate (18).

The St. Gallen expert consensus meeting classified $\geq 4$ nodes in axilla as a high-risk group (19). With respect to the adjuvant therapy regimen, in the study by Saarto, premenopausal patients received chemotherapy with one regimen consisting of six cycles of CMF. On the other hand, postmenopausal patients received only endocrine therapy consisting of tamoxifen or tremifen, including hormonal receptor-negative patients. In an in vivo model of a human breast cancer cell line, bisphosphonate without anti-cancer drugs decreased tumor burden in the bone, but increased tumor accumulation in soft-tissue organs (20). Thus, an increase in non-osseous metastases may occur in patients who do not receive effective adjuvant therapy. In the present study, patients received standard adjuvant chemotherapy. Hormonal receptor status was also taken into account in decisions regarding endocrine therapy.

We used $45 \mathrm{mg}$ of pamidronate every 2 weeks for a total of 4 infusions in this prevention study. Pamidronate is a potent bisphosphonate and has a long half-life in the bone (at least 300 days) (21). Furthermore, the administration of intravenous pamidronate is more effective than that of oral bisphosphonates. The selection was based on the findings, from the treatment of bone metastases, that almost all clinical effects had been obtained with only 4 infusions of pamidronate ( 45 $\mathrm{mg}$ ). The possibility of adverse effects with over-administration, especially the long-term suppression of bone turnover in disease-free patients was also considered. It is not known whether long-term prophylactic administration is effective in the prevention of the development of bone metastases. Adjuvant systemic chemotherapy is usually performed with short-term administration. If 4 infusions of $45 \mathrm{mg}$ pamidronate were to have a beneficial effect, this would greatly impact the bisphosphonate studies. Patients would therefore obtain not only direct cost benefits, but also indirect effects in terms of quality of life.

Gnant et al recently reported on an adjuvant zoledronic acid study in 1801 premenopausal endocrine-positive patients at the June 2008 ASCO meeting (Chicago, IL) (22). Zoledronic acid has the strongest inhibitory activity against bone resorption and shows direct anti-tumor activity and immune activation ( $\gamma \delta \mathrm{T}$ cell proliferation). These patients were randomized to goserelin with tamoxifen or anastrozole plus intravenous zoledronic acid (4 mg every 6 months) for 3 years. With a median follow-up of 60 months, disease-free survival was significantly higher in the zoledronic acid group than in the group administered with endocrine therapy alone (hazard ratio $=0.64 ; \mathrm{p}=0.01$ ). The addition of zoledronic acid significantly reduced the risk of relapse-free survival events by $35 \%(p=0.015)$ compared with that of endocrine therapy alone. For overall survival, there was a non-significant trend favoring zoledronic acid treatment (hazard ratio $=0.60$; $\mathrm{p}=0.10$ ). These results were considered to be similar to our results by mechanism of potent bisphosphonate.

An ongoing definitive adjuvant clodronate study, NSABP B-34, has randomized early breast cancer patients to a clodronate (3 years) or placebo group. Adjuvant chemotherapy and/or hormonal therapy have been applied. Other ongoing trials include the AZURE and SWOG (0307)/intergroup trials. The AZURE trial aims to evaluate the effect of adjuvant zoledronic acid (zoledronic acid administration for 5 years). The SWOG (0307)/intergroup trial will compare intravenous zoledronic acid with oral clodronate and risedronate (3 years). The ASCO guideline states that an optimal agent, dose, route of therapy, schedule and duration of therapy of bisphosphonate for the prevention of bone metastases in breast cancer patients remain unknown. Our study was a small and non-randomized trial. However, its findings have encouraged further investigation in a large population with a view to confirming these results. At present, zoledronic acid is the most potent bisphosphonate. Thus, we plan to perform a larger randomized study of zoledronic acid for the prevention of the development of bone metastases in breast cancer patients at high risk for bone metastasis. Further investigations will confirm the significant effects of adjuvant bisphosphonate therapy in patients at high risk for bone metastasis.

\section{References}

1. Rodan GA and Fleisch HA: Bisphosphonates: mechanisms of action. J Clin Invest 97: 2692-2696, 1996.

2. Hortobagyi GN, Theriault RL, Porter L, Blayney D, Lipton A, Sinoff C, Wheeler H, Simeone JF, Seaman J and Knight RD: Efficacy of pamidronate in reducing skeletal complications in patients with breast cancer and lytic bone metastases. Protocol 19 Aredia Breast Cancer Study Group. N Engl J Med 335: 1785-1791, 1996.

3. Hughes DE, Wright KR, Uy HL, Sasaki A, Yoneda T, Roodman GD, Mundy GR and Boyce BF: Bisphosphonates promote apoptosis in murine osteoclasts in vitro and in vivo. J Bone Miner Res 10: 1478-1487, 1995.

4. Jagdev SP, Coleman RE, Shipman CM, Rostami HA and Croucher PI: The bisphosphonate, zoledronic acid induces apoptosis of breast cancer cells: evidence for synergy with paclitaxel. Br J Cancer 84: 1126-1134, 2001.

5. Crohns CA, Untch M and Konecny G: Different bisphosphonates have direct cytotoxic effects on three breast cancer cell lines and fresh breast cancer tumor tissue. Proc Am Soc Clin Oncol 20: abs. 2005, 2001.

6. Santini D, Vespasiani Gentilucci U, Vincenzi B, Picardi A, Vasaturo F, La Cesa A, Onori N, Scarpa S and Tonini G: The antineoplastic role of bisphosphonates: from basic research to clinical evidence. Ann Oncol 14: 1468-1476, 2003.

7. Teronen O, Heikkila P, Konttinen YT, Laitinen M, Salo T, Hanemaaijer R, Teronen A, Maisi P and Sorsa T: MMP inhibition and down-regulation by bisphosphonates. Ann NY Acad Sci 878: 453-465, 1999.

8. Paterson AH: The potential role of bisphosphonates as adjuvant therapy in the prevention of bone metastases. Cancer 88: 3038-3046, 2000.

9. Sasaki A, Boyce BF, Story B, Wright KR, Chapman M, Boyce R, Mundy GR and Yoneda T: Bisphosphonate risedronate reduces metastatic human breast cancer burden in bone in nude mice. Cancer Res 55: 3551-3557, 1995.

10. Van der Pluijm G, Vloedgraven H, Van BeekE, Van der Wee-Pals L, Lowik $\mathrm{C}$ and Papapoulos S: Bisphosphonates inhibit the adhesion of breast cancer cells to bone matrices in vitro. J Clin Invest 98: 698-705, 1996.

11. Diel IJ, Solomayer EF, Costa SD, Gollan C, Goerner R, Wallwiener D, Kaufmann M and Bastert G: Reduction in new metastases in breast cancer with adjuvant clodronate treatment. N Engl J Med 339: 357-363, 1998.

12. Diel IJ, Solomayer EF, Gollan C, Schutz F and Bastert G: Bisphosphonates in the reduction of metastases in breast cancer - results of the extended follow-up of the first study population. Proc Am Soc Clin Oncol 19: abs. 314, 2000.

13. Jaschke A, Bastert G, Solomayer EF, Costa S, Schuetz F and Diel IJ: Adjuvant clodronate treatment improves the overall survival of primary breast cancer patients with micrometastases to bone marrow - a longtime follow-up. J Clin Oncol 22: abs. 529, 2004. 
14. Powles T, Paterson S, Kanis JA, McCloskey E, Ashley S, Tidy A, Rosenqvist K, Smith I, Ottestad L, Legault S, Pajunen M, Nevantaus A, Mannisto E, Suovuori A, Atula S, Nevalainen J and Pylkkanen L: Randomized placebo-controlled trial of clodronate in patients with primary operable breast cancer. J Clin Oncol 20: 3219-3224, 2002.

15. Powles T, Paterson A, McCloskey E, Kurkilahti M and Kanis J: Oral clodronate for adjuvant treatment of operable breast cancer: results of a randomized, double-blind, placebo-controlled multicenter trial. J Clin Oncol 22: abs. 528, 2004.

16. Saarto T, Blomqvist C, Virkkunen P and Elomaa I: Adjuvant clodronate treatment does not reduce the frequency of skeletal metastases in node-positive breast cancer patients: 5-year results of a randomized controlled trial. J Clin Oncol 19: 10-17, 2001.

17. Saarto T, Vehmanen L, Blomqvist $C$ and Elomaa I: Ten-year follow-up of a randomized controlled trial of adjuvant clodronate treatment in node-positive breast cancer patients. J Clin Oncol 22: abs. 527, 2004

18. Colleoni M, O'Neill A, Goldhirsch A, Gelber RD, Bonetti M, Thurlimann B, Price KN, Castiglione-Gertsch M, Coates AS, Lindtner J, Collins J, Senn HJ, Cavalli F, Forbes J, Gudgeon A, Simoncini E, Cortes-Funes H, Veronesi A, Fey M and Rudenstam CM: Identifying breast cancer patients at high risk for bone metastases. J Clin Oncol 18: 3925-3935, 2000.
19. Goldhirsch A, Wood WC, Gelber RD, Coates AS, Thurlimann B and Senn HJ: Progress and promise: highlights of the international expert consensus on the primary therapy of early breast cancer 2007. Ann Oncol 18: 1133-1144, 2007.

20. Michiqami T, Wiliams $\mathrm{P}$ and Dallas M: Bisphosphonate may increase metastases to soft tissue sites in breast cancer and B-cell lymphoma. J Bone Miner Res 12 (Suppl. 1): s106, abs. 115, 1997.

21. Leyvraz S, Hess U, Flesch G, Bauer J, Hauffe S, Ford JM and Burckhardt P: Pharmacokinetics of pamidronate in patients with bone metastases. J Natl Cancer Inst 84: 788-792, 1992.

22. Gnant M, Mlineritsch B, Schippinger W, Luschin-Ebengreuth G, Poestlberger S, Menzel C, Jakesz R, Kubista E, Marth C, Greil R and on behalf of the ABCSG: Adjuvant ovarian suppression combined with tamoxifen or anastrozole, alone or in combination with zoledronic acid, in premenopausal women with hormoneresponsive, stage I and II breast cancer: First efficacy results from ABCSG-12. J Clin Oncol 26: abs. LBA4, 2008. 